\section{AVALIAÇÃO DE DESEMPENHO DO PROGRAMA ACADEMIA DA SAÚDE EM BELO HORIZONTE: UM ESTUDO DE CASO}

\author{
PERFORMANCE EVALUATION OF THE HEALTH GYM PROGRAM IN BELO \\ HORIZONTE: A CASE STUDY
}

\author{
EVALUACIÓN DE DESEMPEÑO DEL PROGRAMA ACADEMIA DE LA SALUD EN \\ BELO HORIZONTE: UN ESTUDIO DE CASO
}

\section{Marcos Gonçalves Maciel*, Luiz Alex Silva Saraiva*, Marcelo Moraes Silva**, Paulo Roberto Vieira Junior ${ }^{\star \star *}$}

\begin{abstract}
Palavras chave
Programas

governamentais.

Eficiência.

Eficácia.

Efetividade.

Resumo: Esta pesquisa realizou uma avaliação de desempenho em um polo do Programa Academia da Saúde em Belo Horizonte/MG. É uma pesquisa qualitativa, descritiva, do tipo estudo de caso. A escolha do polo e dos participantes foi intencional. Adotamos a entrevista em profundidade para a coleta dos dados, sendo que a amostra foi estipulada pela técnica de saturação. Para a interpretação das informações usamos a análise crítica do discurso. Os resultados indicam algumas lacunas existentes no programa, como aspectos logísticos adequados; inadequação da articulação entre polo e Unidade Básica de Saúde; ausência de metas definidas. Como aspectos positivos identificamos a satisfação dos profissionais em atuar no programa e dos alunos em participar das aulas. Concluímos que o modelo de avaliação adotado contribuiu para diagnosticar importantes condições operacionais executadas que podem auxiliar a tomada de decisões dos gestores quanto ao desenvolvimento do programa.
\end{abstract}

Keywords: Government Programs. Efficiency. Efficacy. Effectiveness.

Palabras clave: Programas gubernamentales. Eficiencia.

Eficacia.

Efectividad.
Abstract: This research conducted a performance evaluation on the Health Gym Program in Belo Horizonte, MG. It is a qualitative case study and the choice of Gym and participants was intentional. We used in-depth interview to collect data and the sample was set by saturation. To interpret the information, we used critical discourse analysis. The results point to some gaps in the program such as proper logistics, coordination between Gym and Basic Health Unit, and clear goals. As positive aspects we found professionals' satisfaction in working in the program and students' satisfaction in participating in the classes. We concluded that the evaluation model adopted contributed to finding important operational conditions that can help managers to make decisions regarding the development of the program.

Resumen: Esta investigación realizó una evaluación de desempeño en un polo del Programa Academia de la Salud en Belo Horizonte/MG. Se trata de una investigación cualitativa, descriptiva, del tipo estudio de caso. La elección del polo y de los participantes fue intencional. Se adoptó la entrevista en profundidad para la recolección de los datos, siendo que la muestra fue estipulada por la técnica de saturación. Para la interpretación de las informaciones usamos el análisis crítico del discurso. Los resultados indican algunas lagunas existentes en el programa, como: aspectos logísticos adecuados, inadecuación de la articulación entre polo y Unidad Básica de Salud; ausencia de metas definidas. Como aspectos positivos, identificamos la satisfacción de los profesionales en actuar en el programa y de los alumnos en participar de las clases. Concluimos que el modelo de evaluación adoptado contribuyó para diagnosticar importantes condiciones operacionales ejecutadas que pueden auxiliar en la toma de decisiones de los gestores en cuanto al desarrollo del programa.
*Universidade do Estado de Minas Gerais. Belo Horizonte, MG, Brasil. E-mail: marcosgmaciel@ hotmail.com; saraivalas@gmail.com

**Universidade Federal do Paraná. Curitiba, PR, Brasil.

E-mail:moraes_marc@yahoo.com.br

***Instituto Federal de Minas Gerais. Santa Luzia, MG, Brasil. E-mail: paulo.vieira@ifmg.edu.br

Recebido em: 04-12-2018 Aprovado em: 20-03-2019 Publicado em: 06-05-2019

DOI https://doi.org/10.22456/1982-8918.88631 (c) (i) (8) Licence 


\section{INTRODUÇÃO}

A implantação de programas governamentais de atividade física (PGAF) tem sido ampliada no Brasil nas últimas duas décadas (MACIEL; COUTO, 2018). Inicialmente alguns municípios inseriram programas denominando-os, por exemplo, como academias da cidade (AMORIM, 2013; BRASIL, 2011). Posteriormente o governo federal, por meio do Ministério da Saúde (MS), adotou ações para o desenvolvimento em todo o território nacional do Programa Academia da Saúde (PAS), como parte integrante da política nacional de promoção da saúde (BRASIL, 2018; BECKER, 2016; MALTA et al., 2009).

O programa investigado no presente estudo foi criado em 2006, pela Secretaria Municipal de Saúde de Belo Horizonte/MG (LAS CASAS, 2014), sendo posteriormente conveniado ao PAS, recebendo uma subvenção que permite custear parte das despesas para o seu desenvolvimento, assim como incorporou determinadas diretrizes metodológicas.

O MS caracteriza o PAS como um equipamento da Atenção Básica em Saúde vinculado ao Sistema Único de Saúde (SUS), de prevenção de agravos e doenças crônicas não transmissíveis, complementando o cuidado individual e coletivo na atenção básica. Tal programa tem como objetivo geral "[...] contribuir para a promoção da saúde e produção do cuidado e de modos de vida saudáveis da população a partir da implantação de polos com infraestrutura e profissionais qualificados [...]" (BRASIL, 2018, p.13).

Dessa forma, essa tipologia de programa assume uma relevância social ao considerar sua contribuição como um dos meios para a promoção da saúde da população (MACIEL; SARAIVA; MARTINS; MEURER, 2018; COELHO; VERDI, 2015; COSTA et al., 2013). Essa expansão tem despertado o interesse da comunidade acadêmica e das instituições promotoras desses programas para a realização de estudos avaliativos das ações desenvolvidas.

Mennecucci (2008) e Munhoz (2008) entendem que os objetivos de programas públicos devem priorizar um conjunto de demandas sociais e não apenas a execução de ações sem a devida articulação com a comunidade local. Conforme Saraiva e Gonçalves (2008), a avaliação de programas públicos apresenta algumas limitações, possivelmente porque os indicadores de desempenho são em muitos casos inadequados, gerando informações pouco úteis para 0 incremento das ações desenvolvidas. De acordo com esses autores, os parâmetros técnicos usados para definir objetivos estratégicos e avaliar o desempenho organizacional mostram-se ineficazes, apontando a necessidade de reenquadramento analítico da atual perspectiva de avaliação do desempenho desses programas. Ademais, segundo os mesmos autores, tais avaliações focam, sobretudo, no aspecto quantitativo, o que por sua vez é insuficiente para responder às variáveis necessárias de comparação de qualificação de desempenho desses programas, isto é, o seu impacto social.

A função primordial da avaliação de desempenho, de acordo com Reifschneider (2008), é demonstrar qualidade, permitindo o desenvolvimento do programa e encorajando riscos que possam elevar padrões. Ainda de acordo com autora, o objetivo da avaliação é orientar os gestores, direcionando-os quanto à continuidade, necessidade de correções ou mesmo suspensão de uma determinada política ou programa.

Umas das modalidades de avaliação que pode ser adotada pelos PGAF, segundo Maciel, Saraiva e Carvalho (2017), é a avaliação de desempenho. Essa modalidade advém 
da área da Administração e consiste na avaliação de três parâmetros: eficiência, eficácia e efetividade.

A eficiência relaciona-se ao uso dos meios, isto é, com o adequado processo de utilização dos recursos para atingir os resultados traçados, sem questionar se são válidos (LACOMBE; HEILBORN, 2008). Segundo Saraiva e Gonçalves (2008), a adoção desse parâmetro é importante em períodos em que os recursos - dinheiro, tecnologia, pessoal - são escassos, porque seu foco recai sobre o processo e sua racionalização.

A eficácia é definida como o cumprimento das metas estipuladas, portanto, está ligada à capacidade de alcance de resultados predefinidos (LACOMBE; HEILBORN, 2008). Assim, esse parâmetro é compreendido em termos dos fatores considerados mais importantes no que se refere à capacidade da organização em adquirir e utilizar recursos na busca dos resultados planejados.

Por fim, a efetividade, concentra-se na racionalidade social, ou seja, pressupõe um compromisso com os objetivos e demandas da sociedade. Em outras palavras, é a capacidade organizacional de atender às demandas do ambiente em que está inserida, com foco nas pessoas envolvidas no processo (LACOMBE; HEILBORN, 2008).

Reifschneider (2008), Ramos e Schabbach (2012) destacam alguns aspectos relevantes que devem ser levados em consideração quanto à realização da avaliação de desempenho em programas sociais para verificar o impacto de suas ações: demanda social, definição das abordagens de avaliação - ex ante, monitoramento, ex post -, quem avaliará, a natureza da avaliação - qualitativa, quantitativa -, categorias de análise, metas e objetivos decididos. Assim sendo, o estabelecimento dessas e tantas outras variáveis permitirá um melhor julgamento para as tomadas de decisões dos gestores públicos sobre o desenvolvimento dos programas.

Ao considerar tais aspectos, o questionamento que fazemos neste artigo é: os PGAF cumprem com seu papel social? A partir desse questionamento, estabelecemos como objetivos:

a) adotar os parâmetros de desempenho para avaliar um polo do PAS em Belo Horizonte;

b) dar voz aos atores sociais que compõem esse programa quanto à sua avaliação.

\section{MATERIAIS E MÉTODOS}

A presente pesquisa caracteriza-se como qualitativa-descritiva, exploratória, do tipo estudo de caso (CRESWELL, 2010). O PAS tem uma coordenação geral e nove coordenadores regionais subordinados à primeira. A obtenção das informações sobre o programa, assim como o acompanhamento da realização da pesquisa, foi realizada por um coordenador regional. Esse profissional, formado em Educação Física, atua somente na parte organizacional, supervisionando um conjunto de polos em sua área; no entanto, já teve experiências de intervenção.

A coleta das informações seguiu uma abordagem intencional, no entanto, foram estabelecidos critérios de inclusão para a seleção dos profissionais de Educação Física e do polo a ser investigado:

a) o coordenador regional deveria aceitar participar da pesquisa, assim como intermediar todo o processo com os profissionais dos polos sob sua supervisão; 
b) o polo deveria ter no mínimo um ano de funcionamento;

c) todos os profissionais de Educação Física deveriam estar há pelo menos um ano atuando no local, e todos deveriam participar da pesquisa.

Compreendemos que esse período estipulado seria adequado para realizar um trabalho de captação e manutenção das pessoas da comunidade local para participar das atividades oferecidas, assim como possibilitar a adaptação dos profissionais ao programa e à comunidade assistida para o desenvolvimento de suas funções. Destacamos que em cada unidade há dois profissionais de Educação Física por turno de atendimento à população - matutino, vespertino e/ou noturno -, portanto, o número de profissionais poder variar de acordo com os turnos oferecidos.

O número de pessoas atendidas em cada polo depende da quantidade de turnos disponibilizados à população e das características das instalações quanto à infraestrutura, sendo que algumas estão alocadas em salões de igrejas, centros comunitários, ginásios poliesportivos municipais ou em instalações construídas especificamente para o programa. No polo investigado havia um turno de atendimento, no período matutino, com um atendimento médio mensal de 300 pessoas.

Em relação à comunidade participante da pesquisa, foram criadas duas categorias, uma composta por alunos frequentes ao programa há pelo menos seis meses - esse tempo foi determinado de modo que pudesse ter sido feita pelo menos uma reavaliação física no polo -, e outra por ex-alunos, que participaram no mínimo três meses das atividades - tempo considerado como minimamente satisfatório para se observar melhoras psicobiossociais com as atividades realizadas. Nesse sentido, também foi adotada a escolha intencional dessas categorias. Para determinar o número de participantes, estipulamos a adoção da amostra por saturação (STRAUSS; CORBIN, 2008).

Um dos profissionais do polo, de posse dos dados cadastrais de todas as pessoas que frequentaram o programa, forneceu a um dos pesquisadores o contato dos ex-alunos, de modo que receberam uma ligação telefônica. Nesse contato, o pesquisador explicou os objetivos da pesquisa e convidou para participar dela. Em relação aos alunos frequentes, um dos profissionais do polo apresentou um dos pesquisadores às turmas. Ele expôs a proposta da pesquisa e estendeu o convite a todos. Identificados os interessados em contribuir com a pesquisa, foram agendados horários individuais para a realização das entrevistas em profundidade.

Para a interpretação dos resultados, usamos a análise crítica do discurso (VAN DIJK, 2012). Entretanto, citaremos apenas algumas falas dos depoentes, embora em sua maioria fossem bastante semelhantes em relação às perguntas realizadas. Todos os participantes responderam às seguintes categorias de análise contemplando os parâmetros de desempenho as dimensões:

a) Satisfação pessoal - aborda os aspectos qualitativos relacionados à satisfação dos envolvidos com o programa, estando alinhado com o parâmetro efetividade;

b) Aspectos Administrativos - foco nos parâmetros eficiência e eficácia ao analisar as condições de trabalho, infraestrutura, capacitação profissional, atendimento aos objetivos elaborados pelo programa. 
A presente pesquisa foi aprovada pelos Comitês de Ética da Universidade onde um dos pesquisadores trabalha, assim como da Secretaria Municipal de Saúde de Belo Horizonte, respectivamente pelos números de protocolos 1.548 .799 e 1.808.411. Para manter o anonimato dos entrevistados, criamos nomes fictícios para os alunos, seguidos de idade, por exemplo: Maria, 68; os profissionais foram identificados como P1 (gestor regional), P2 e P3.

\section{RESULTADOS E DISCUSSÃO}

Foram entrevistados três profissionais, bacharéis em Educação Física, com média de 29,6 anos de idade, 6,3 anos de tempo de formação acadêmica e 3,6 anos de trabalho no programa. Desses, um é coordenador regional do programa e dois são professores na unidade investigada. Em relação à comunidade assistida, incluindo ex-alunos e alunos regulares, participaram 21 pessoas, com média de idade de 53,3 anos. Os demais dados sociodemográficos são apresentados no Quadro 1.

Quadro 1 - Dados sociodemográficos dos alunos e ex-alunos do programa

\begin{tabular}{|c|c|c|c|c|c|c|}
\hline Categorias & $\mathrm{N}$ & Sexo & Idade & Escolaridade & Estado Civil & Profissão \\
\hline \multirow{14}{*}{ Alunos } & 1 & $\mathrm{~F}$ & 68 & Grupo Completo* & Viúva & Aposentada \\
\hline & 2 & $\mathrm{M}$ & 60 & Grupo Completo & Casado & Aposentado \\
\hline & 3 & $\mathrm{~F}$ & 60 & Grupo Completo & Casada & Do lar \\
\hline & 4 & $F$ & 41 & Fund. Incompleto & Casada & Do lar \\
\hline & 5 & $\mathrm{~F}$ & 40 & E.M. Completo** & Casada & Do lar \\
\hline & 6 & $F$ & 53 & E.M. Completo & Casada & Do lar \\
\hline & 7 & $M$ & 64 & Fund. Incompleto & Casado & Aposentado \\
\hline & 8 & $\mathrm{~F}$ & 55 & Fund. Completo & Casada & Costureira \\
\hline & 9 & $\mathrm{M}$ & 54 & Fund. Completo & Divorciado & Aposentado \\
\hline & 10 & $M$ & 66 & Grupo Completo & Casado & Aposentado \\
\hline & 12 & $M$ & 44 & Fund. Incompleto & Divorciado & Pedreiro (Pensionista INSS) \\
\hline & 13 & $M$ & 62 & E.M. Completo & Casado & Aposentado \\
\hline & 14 & $\mathrm{~F}$ & 37 & E.M. Completo & Casada & Do lar \\
\hline & 15 & $\mathrm{~F}$ & 38 & Médio Incompleto & Viúva & Depiladora \\
\hline \multirow{7}{*}{ Ex-alunos } & 1 & $F$ & 40 & Fund. Incompleto & Casada & Do lar \\
\hline & 2 & $\mathrm{~F}$ & 62 & E.M. Completo & Viúva & Aposentada \\
\hline & 3 & $\mathrm{M}$ & 78 & Grupo Completo & Casado & Aposentado \\
\hline & 4 & $\mathrm{~F}$ & 65 & Grupo Completo & Casada & Do lar \\
\hline & 5 & M & 21 & E.M. Completo & Solteiro & Desempregado \\
\hline & 6 & $\mathrm{~F}$ & 40 & Fund. Incompleto & Casada & Do lar \\
\hline & 7 & $\mathrm{~F}$ & 40 & Fund. Incompleto & Casada & Do lar \\
\hline
\end{tabular}

Fonte: Dados da pesquisa. * Referente à antiga 1aa a $4^{\text {a }}$ série. ${ }^{* *}$ Ensino Médio

\subsection{AVALIAÇÃO DO PARÂMETRO EFICÁCIA}

O objetivo do programa estudado é promover a saúde e os cuidados à saúde da população (BRASIL, 2018). Todavia, esses construtos estão relacionados aos fatores sociodemográficos e econômicos, em uma inter-relação complexa e multidimensional (DEVIDE, 2002), que somente por meio da intervenção da atividade física não é possível alcançá-los (MACIEL; SARAIVA; MARTINS; MEURER, 2018). 
A metodologia adotada pelo programa em questão para o controle das variáveis clínicas, antropométricas e subjetivas relacionadas à saúde foi realizada por meio de uma avaliação diagnóstica, no caso dos alunos novatos, e uma reavaliação a cada seis meses de todos os que estavam regularmente participantes. Essa avaliação consiste na verificação das variáveis clínicas, antropométricas e estilo de vida (LAS CASAS et al., 2014). No entanto, segundo esses mesmos autores, não existe o estabelecimento de metas específicas a serem alcançadas ao final de um determinado período, seja por parte dos alunos ou da instituição. Quando perguntado a P1 sobre o não estabelecimento de metas institucionais concretas, ele alegou, sobretudo, o fato da rotatividade dos alunos nos polos:

Planejamento pra isso fica é um pouco complicado; porque esse público é acíclico.
Às vezes, a pessoa tá comigo essa semana, na semana que vem já não tá mais!
[...] Mas a gente tem comparação, por exemplo, se eu comparar 2013 com 2014,
se houve uma redução. Por exemplo, a nossa meta é assim: aumentar cada
vez mais o público de idoso, a gente quer mais idoso, mais hipertensos, mais
diabéticos, mais obesos [...]. Mas assim, meta instaurada não! A gente compara
um ano com o outro!

Perguntamos aos ex-alunos e alunos se percebiam melhorias em sua saúde e a quase totalidade dos entrevistados respondeu positivamente, denotando uma eficácia em relação à percepção de bem-estar ou de melhorias em determinadas variáveis antropométricas:

Ajudou, ajudou muito, redução do cansaço, melhorou a disposição, fico mais tranquila, mais calma (Maria, 68).

Sim, porque de seis em seis meses a gente faz avaliação, a minha tá sempre melhor! O percentual de gordura tá normal, o peso tá normal! (Wagner, 66).

Todavia, é importante ressaltar que o uso de avaliações do tipo causa e efeito, avaliação e reavaliação, considerando apenas a prática da atividade física por si só com determinadas alterações clínicas e/ou antropométricas - não considerando outras variáveis relacionadas aos fatores determinantes à saúde - não são satisfatórias para estabelecer uma relação linear e causal benéfica por meio dessa atividade. Assim, tais avaliações de forma isolada são insuficientes para se compreender a realidade de um fenômeno multifatorial e multidimensional como a saúde (KUSMA; MOYSÉS; MOYSÉS, 2012; LIMA et al., 2004).

Outro importante ponto a ser observado sobre a determinação da eficácia diz respeito à caracterização de uma avaliação da promoção da saúde proposta pela International Union for Health Promotion and Education (2000). Para essa instituição, a eficácia deve proporcionar mudanças nos determinantes da saúde da população-alvo. Esses determinantes incluem tanto aqueles que estão sob o controle das pessoas - condutas individuais, estilo de vida, utilização dos serviços de saúde - como os que estão fora de seu controle - condições sociais, econômicas e ambientais, assim como a prestação de serviços à saúde. Portanto, a avaliação em saúde deve considerar tanto os aspectos individuais quanto os socioambientais. Nesse sentido, identificamos a insatisfação dos alunos em relação ao atendimento na UBS:

A gente vai ao posto de saúde, não encontra remédio. Precisei de remédio e tive que comprar; minha esposa a mesma coisa, não tinha remédio de pressão, há uns quatro meses (Wagner, 66).

Eu acho que deveria ter mais médico (se referindo ao posto de saúde), remédio, vacina [...] e eu não acho que a prefeitura não tem condição de ter esse remédio, não! (Cléria, 60). 
Assim, para determinar a eficácia de um programa é necessário comparar os resultados previamente estipulados com os alcançados após as ações realizadas (RAMOS; SCHABBACH, 2012; MAXIMIANO, 2009). Ademais, deveria haver procedimentos que isolassem determinadas variáveis relacionas à prática da atividade física oferecida no polo, com as demais ações realizadas além das aulas nesse local, como, por exemplo, com as mudanças comportamentais - hábitos alimentares, qualidade do sono, consumo de bebidas alcoólicas - e dados vinculados ao atendimento relacionado ao acompanhamento periódico do controle de doenças crônicas já apresentadas por alguns alunos. Afinal não se pode estabelecer uma relação linear, causa e efeito, entre a prática da atividade física, ações de educação da saúde e a efetiva obtenção da saúde, sem considerar a inter-relação com os demais fatores determinantes da saúde.

Diante dessa complexidade, não basta apenas afirmar que o programa apresentou resultados favoráveis - melhoras antropométricas, percepção de bem-estar dos participantes -, embora seja importante estabelecer a evidência daquilo que funcionou em sua execução. Mas, também, é preciso especificar como e por quê este ou aquele procedimento foi satisfatório não apenas de forma isolada, mas também associado com o objetivo do programa.

Outro ponto importante a ser refletido sobre a eficácia do programa é a dimensão do atendimento à população. No ano de 2013, segundo Las Casas et al. (2014), em Belo Horizonte o programa atendeu pouco mais de 24 mil pessoas nas nove regionais. Ao considerar que a população da referida cidade é de aproximadamente dois milhões e meio de pessoas, 0 número de atendimentos representa menos de um por cento da população total. À luz dessa observação, não desconsideramos a importância social do programa, pelo contrário. Mas, como é estabelecida uma proposta ampla, ou seja, atender a população, embora pouco provável que se contemple sua totalidade, devemos refletir sobre a pretensão de que o programa possa ser eficaz quanto ao seu objetivo, considerando a escala populacional.

No polo em questão, 300 pessoas frequentam as atividades regularmente, sendo que esse número permanecerá ao longo de todo 0 ano, pois não havia planos para a expansão das atividades para outros turnos. Dessa forma, não se ampliará o atendimento à população, sobretudo, às pessoas que trabalham durante 0 dia e só podem participar das aulas à noite. Novas adesões só ocorrerão quando houver alguma desistência de algum aluno, pois a capacidade de atendimento é limitada.

Em síntese, ao considerar as características operacionais do programa e da metodologia adotada para o seu monitoramento, questionamos se podemos afirmar concretamente que ele seja eficaz em seu todo. Como dito, não desvalorizamos os aspectos sociais, assim como as melhorias das percepções de bem-estar individuais promovidos pelo programa às pessoas assistidas.

\subsection{AVALIAÇÃO DO PARÂMETRO EFICIÊNCIA}

Para alcançar a promoção da saúde da população por meio do programa, o poder público deve usar eficientemente os recursos necessários, sejam humanos, financeiros, logísticos, administrativos, com a articulação entre áreas afins e interligadas. Esses aspectos remetem ao parâmetro eficiência. Este busca utilizar os meios e procedimentos mais adequados, independentemente dos resultados alcançados (MAXIMIANO, 2009; LACOMBE; HEILBORN, 2008). Conforme esses autores, o conceito de eficiência está atrelado ao desempenho do processo. 
Assim sendo, ao considerar que a proposta do programa está vinculada à do SUS, esperava-se que houvesse uma linha de ação dessa rede que possibilitasse 0 alcance dos objetivos traçados. No entanto, essa não foi a realidade encontrada no polo investigado:

[...] Tem polo do Núcleo de Assistência à Saúde da Família que apoia, e tem polo que não apoia! [...] Às vezes o professor da ponta tá precisando de um fisioterapeuta, o fisioterapeuta não vem, tá com agenda cheia. Então, assim, acho que eles não enxergaram ainda, não que eles não enxergaram, mas tá meio complicado essa articulação devido à agenda deles (P1).

Há centro de saúde onde não tem uma academia vinculada, não sabem o que é, não tem interesse em saber! Eles não têm muita noção de como funciona o projeto! Mas a gente tá mudando isso! Todo mês tem uma reunião de matriciamento, que é a reunião do NASF com o pessoal do centro de saúde (P3).

Percebemos pelas falas dos profissionais uma insatisfação quanto ao processo de interação entre o polo e a UBS no que diz respeito ao atendimento ao aluno. Além da inexistência de um protocolo de atendimento recíproco - programa e UBS -, também há desconhecimento e não valorização por parte de alguns profissionais da UBS quanto ao objetivo do programa. No entanto, esse hiato compromete a prestação de serviço de qualidade à população, tendo em vista que a premissa do programa é sua interlocução com a APS e as UBS (BRASIL, 2018).

Outro aspecto relevante é a identificação da ineficiência do processo quanto à manutenção dos equipamentos necessários à operacionalização do programa. Esse fato é apontado por P1 e P2, ou seja, tanto na visão do gestor quanto do profissional que trabalha na intervenção direta com a população. Os profissionais relatam a existência de falhas no processo de manutenção e obtenção de equipamentos, desde os usados nas aulas, até os destinados a tarefas administrativas. Essa percepção é corroborada pelos alunos que igualmente estão insatisfeitos em relação a alguns aspectos operacionais do programa:

Precisa ter a noite, pras pessoas que trabalham, né? (Maria, 68).

Acho que o espaço, o espaço é pequeno! Eu acho que a sala poderia ser maior! Porque aí teria mais aluno! [...] são poucos os materiais disponíveis; tem que ficar revezando os materiais (Marta, 41 ).

As análises feitas permitiram identificar, pelo menos no polo investigado, a presença de uma ineficiência do processo operacional conduzido pelo poder público, na demora da aquisição e/ou substituição de equipamentos fundamentais para a viabilização satisfatória do programa.

\subsection{AVALIAÇÃO DO PARÂMETRO EFETIVIDADE}

A efetividade foca-se nos aspectos sociais em detrimento dos processos e resultados alcançados, assim como deve estar vinculada simultaneamente à obtenção satisfatória dos parâmetros eficácia e eficiência. No entendimento de Westphal e Mendes (2009), esse parâmetro caracteriza-se enquanto análise fenomenológica em detrimento da quantitativa. Portanto, não basta uma organização ser eficiente e/ou eficaz se não promove o sentimento de satisfação do seu público interno e externo (MAXIMIANO, 2009; LACOMBE; HEILBORN, 2008). Nesse sentido, ao analisarmos os dados referentes a esse parâmetro, encontramos um paradoxo a respeito da satisfação com o programa. Existe uma satisfação dos alunos e ex- 
alunos com as atividades desenvolvidas no programa. No entanto, há uma insatisfação com o atendimento na UBS, assim com a infraestrutura disponibilizada no polo:

Uai, eu acho que a academia pra mim tem tanta importância quanto o almoço e a janta. Eu acho que não conseguiria viver sem a academia! (Regina, 60).

Eu acho que deveria ter mais médico (se referindo ao posto de saúde), remédio, vacina [...] e eu não acho que a prefeitura não tem condição de ter esse remédio, não! (Cléria, 60).

Por sua vez, identificamos esse mesmo paradoxo em relação aos profissionais. Eles estão satisfeitos com o trabalho realizado; todavia, igualmente é relatada uma insatisfação com as condições de trabalho oferecidas pelo poder público:

Com o meu trabalho, sim! Muito satisfeita! Acho que dou o melhor que eu posso dentro da minha qualificação, dentro da minha formação, dentro do meu entendimento sobre atividade física pra essas pessoas que estão aqui; dentro da minha formação pessoal, né! Eu acho que dou esse melhor, e me sinto satisfeita com isso! (P2).

Esses dados são divergentes em relação ao componente satisfação. Inferimos que 0 sentimento positivo desse elemento possa dar-se em virtude das boas relações interpessoais existentes entre os alunos, alunos-profissionais e os profissionais entre si. De maneira oposta, existe insatisfação tanto com a infraestrutura disponibilizada para as atividades quanto com a interação com a UBS. Diante de tal realidade podemos questionar se o programa apresenta efetividade.

Concordamos com Saraiva e Gonçalves (2008), ao afirmarem sobre as limitações do uso da avaliação de desempenho em programas sociais. Assim, levantamos o seguinte questionamento: se a efetividade deve contemplar concomitantemente a satisfação dos públicos interno e externo, além de, também, de ter uma interação positiva com os parâmetros eficiência e eficácia, a adoção do modelo de avaliação de desempenho usado nesta pesquisa seria compatível em programas complexos como o PAS? Essa reflexão pode ser explorada em novos estudos a serem realizados, pois extrapola a proposta da presente investigação.

Em síntese, ao refletirmos sobre a relevância social assumida pelo PAS, o meio acadêmico e as instituições que 0 implementam precisam ponderar sobre quais abordagens metodológicas de avaliações são mais apropriadas, tendo em vista os objetivos e características do programa.

No entanto, seria prudente antes mesmo da implantação de novos polos, assim como os já em andamento, que os gestores públicos diagnosticassem os aspectos relevantes que influenciam no seu adequado desenvolvimento. Por exemplo: o programa atende os anseios e demandas da comunidade local, considerando suas peculiaridades culturais, climáticas, topográficas e perfil populacional? 0 profissional que avaliará as diferentes variáveis - não apenas as clínicas e antropométricas - que o envolvem está devidamente preparado? Qual natureza avaliativa será utilizada - qualitativa, quantitativa, mista - para cada categoria de variável que compreende o programa? Quais instrumentos avaliativos serão adotados questionários, entrevistas, indicadores? Haverá uma triangulação das análises realizadas? Quais recursos são necessários - financeiros, humanos, materiais, logísticos - para a devida implantação e manutenção do programa? Quais metas serão estipuladas e como serão avaliadas - qual a referência adotada para definir esses parâmetros de indicadores? Esse rol 
de perguntas facilmente pode ser ampliado diante da complexidade que envolve a temática em questão. Todavia, este artigo não tem a pretensão de responder esses questionamentos, mas, sobretudo, contribuir ao despertar a atenção para refletir sobre os aspectos elencados.

\section{CONSIDERAÇÕES FINAIS}

O presente artigo se propôs a realizar uma avaliação de desempenho em um polo do PAS em Belo Horizonte. Como mostrado no decorrer do texto, essa modalidade de avaliação é composta pelos parâmetros eficiência, eficácia e efetividade. A análise realizada permitiu identificar alguns aspectos positivos no desenvolvimento do programa. $O$ elemento mais evidente foi relativo ao estabelecimento de vínculos sociais entre as pessoas envolvidas no programa, alunos e profissionais. Essas relações interpessoais atuam como relevante agente motivador para manutenção dos alunos no programa, assim como promovem a satisfação dos profissionais com o trabalho desenvolvido. Outro ponto profícuo detectado é a percepção da melhoria do bem-estar geral, de alguns fatores clínicos e antropométricos dos alunos. Esses resultados mostram que o programa cumpre em parte seus objetivos.

Entre as fragilidades diagnosticadas, podemos listar:

a) deficiência do processo operacional do programa;

b) inadequada interação do polo com a UBS;

c) insatisfação dos alunos e profissionais com a infraestrutura oferecida;

d) o não estabelecimento de metas concretas relacionadas ao alcance do objetivo do programa, tendo como uma das barreiras apontadas a rotatividade dos alunos;

e) dificuldades de controlar as variáveis inerentes ao programa para avaliar o alcance do objetivo tendo em vista a relação da prática e eficácia da atividade física como promotora da saúde.

Em função das peculiaridades que permeiam o programa e as características do modelo de avaliação adotado nesta pesquisa, encontramos um contraste nos resultados no polo investigado, não permitindo afirmar categoricamente se os parâmetros analisados são satisfatoriamente atendidos.

É importante também ressaltar as limitações desta investigação. Devido às decisões metodológicas tomadas e pela opção de realizar um estudo de caso, não é possível realizarmos generalizações dos resultados obtidos quanto ao programa em seu todo. No entanto, essa modalidade de investigação permite compreender de forma mais aprofundada o objeto em questão. Dessa forma, a adoção da análise qualitativa, dando voz aos atores sociais que compõem o programa, com o uso das categorias de análise empregadas pelo parâmetro de desempenho, possibilitou o desvendamento de forma mais profunda das relações interpessoais, profissionais e operacionais do programa.

No entanto, ao propor a adoção do modelo de avaliação de desempenho empregado neste trabalho, pretendemos trazer à luz discussões a respeito dos diferentes olhares envolvendo a utilização das distintas abordagens avaliativas que podem ser aplicadas em PGAF.

É premente que os gestores públicos tenham consciência da multiplicidade de fatores inter-relacionados e interdependentes das inúmeras variáveis que envolvem a temática 
discutida. Dessa forma, devem-se considerar o objetivo do programa e as escolhas das abordagens avaliativas a serem adotadas. Afinal, a não observância desses aspectos pode acarretar uma avaliação imprecisa e refletir negativamente nas tomadas de decisões sobre a implantação, manutenção e até mesmo o encerramento de um programa.

Por fim, a avaliação de um programa tão complexo como o investigado requer um amplo planejamento, iniciando-se em sua elaboração, perpassando pelas etapas de implantação e desenvolvimento. Portanto, um único modelo de avaliação não será suficiente para atender todas as variáveis inerentes ao programa. Dessa forma, é premente e saudável a adoção de diferentes concepções de avaliações ao longo de todo seu processo de desenvolvimento, assim como a devida capacitação dos agentes que conduzirão essas ações, de forma a possibilitar aos gestores públicos as tomadas de decisões mais adequadas, considerando as necessidades e características das comunidades assistidas.

\section{REFERÊNCIAS}

AMORIM, Tales; KNUTH, Alan G.; CRUZ, Daniele, K.A.; MALTA, Deborah C.; REIS, Rodrigo Siqueira; HALLAL, Pedro Curi. Descrição dos programas municipais de promoção da atividade física financiados pelo Ministério da Saúde. Revista Brasileira de Atividade Física e Saúde, v. 18, n. 1, p. 63-74, 2013.

BECKER, Leonardo Augusto; GONÇALVES, Priscila Bezerra; REIS, Rodrigo Siqueira. Programas de promoção da atividade física no Sistema Único de Saúde brasileiro: revisão

Sistemática. Revista Brasileira de Atividade Física e Saúde, v, 21, n. 2, p. 10-122, 2016.

BRASIL. Ministério da Saúde. Secretaria de Vigilância em Saúde. Departamento de Vigilância de Doenças e Agravos não Transmissíveis e Promoção da Saúde. Panorama nacional de implementação do Programa Academia da Saúde: monitoramento nacional da gestão do Programa Academia da Saúde: Ciclo 2016. Brasília, 2018.

BRASIL. Ministério da Saúde. Secretaria de Vigilância em Saúde. Avaliação da efetividade de programas de atividade física no Brasil. Brasília, 2011.

COELHO, Cecília Stahelin; VERDI, Marta Inez Machado. Políticas e programas de atividade física: uma crítica à luz da promoção da saúde. Saúde \& Transformação Social, v. 6, n. 3, p. 96-108, 2015.

COSTA, Bruna Vieira de Lima; MENDONÇA, Raquel de Deus; SANTOS, Luana Caroline; PEIXOTO, Sérgio Viana; ALVES, Marília; LOPES, Aline Cristine Souza. Academia da Cidade: um serviço de promoção da saúde na rede assistencial do Sistema Único de Saúde. Ciência \& Saúde Coletiva, v. 18, n. 1, p. 95-102, 2013.

CRESWELL, John. Projeto de pesquisa: métodos qualitativo, quantitativo e misto. Porto Alegre: Artmed, 2010.

DEVIDE, Fabiano. Educação Física, Qualidade de Vida e Saúde: campos de intersecção e reflexões sobre a intervenção. Movimento, v. 8, n. 2, p.77-84, 2002. 
INTERNATIONAL UNION FOR HEALTH PROMOTION AND EDUCATION (IUHPE). The Evidence of Health Promotion Effectiveness: A Report for the European Commission. $2^{\text {nd }} \mathrm{ed}$. Luxembourg, 2000.

KUSMA, Solena Ziemer; MOYSÉS, Simone Tetu; MOYSÉS, Samuel Jorge. Promoção da saúde: perspectivas avaliativas para a saúde bucal na atenção primária em saúde. Caderno de Saúde Pública, v. 28, Supl, p. S9-S19, 2012.

LACOMBE, Francisco; HEILBORN, Gilberto. Administração: Princípios e Tendências. 2. ed. São Paulo: Saraiva. 2008.

LAS CASAS, Rony Carlos Rodrigues et al. 0 profissional de educação física no sistema único de saúde de Belo Horizonte. In: NOCE, Franco (coord.). O profissional de educação física na área da saúde. Belo Horizonte: EEFFTO, 2014, p. 117-128.

LIMA, Vera Lucia Góes Pereira et al. Análise da eficácia de programas sociais de promoção da saúde realizados em condições macroestruturais adversas. Ciência \& Saúde Coletiva, v. 9, n. 3, p. 679-696, 2004.

MACIEL, Marcos Gonçalves; COUTO, Ana Cláudia Porfírio. Programas governamentais de atividade física: Uma proposta de política pública. Perspectivas em Políticas Públicas, v. 11, 22, p. 55-79, 2018.

MACIEL, Marcos Gonçalves; SARAIVA, Luiz Alex Silva; MARTINS, José Clerton de Oliveira; MEURER, Simone Teresinha. Análise discursiva sobre promoção da saúde no programa academia da cidade de Belo Horizonte. Revista Brasileira de Ciências do Esporte, 2018. Disponível em: https://doi.org/10.1016/j.rbce.2018.03.007. Acesso em: 24 out. 2018.

MACIEL, Marcos Gonçalves; SARAIVA, Luiz Alex Silva; CARVALHO, Mariana Nunes. Avaliação de programas sociais de atividade física: notas conceituais sobre a efetividade como parâmetro de desempenho. Licere, v. 20, n. 2, p. 455-482, 2017.

MALTA, Deborah Carvalho; CASTRO, Adriana Miranda; GOSCH, Cristiane Scolari; CRUZ, Danielle Keylla Alencar. A Política Nacional de Promoção da Saúde e a agenda da atividade física no contexto do SUS. Epidemiologia em Serviços de Saúde, v.18, n.1, p. 79-86, mar. 2009.

MAXIMIANO, Antônio César Amarú. Fundamentos de Administração: Manual compacto para disciplinas de TGA e introdução à Administração. São Paulo: Atlas. 2009.

MENECUCCI, Telma. Políticas de esporte e lazer: $O$ estado da arte e um objeto em construção. In: ISAYAMA, Helder Ferreira; LINHARES, Meily Assbú. Avaliação de políticas e políticas de avaliação: Questões para o esporte e lazer. Belo Horizonte. Editora UFMG, 2008. p. 209-235.

MUNHOZ, Virna Carolina Carvalho. O lazer como direito social na prefeitura de Belo Horizonte. In: ISAYAMA, Helder Ferreira; LINHARES, Meily Assbú. Avaliação de políticas e políticas de avaliação: Questões para o esporte e lazer. Belo Horizonte: Editora UFMG, 2008. p. 179-201.

RAMOS, Marília Patta; SCHABBACH, Letícia Maria. O estado da arte da avaliação de políticas públicas: Conceituação e exemplos de avaliação no Brasil. Revista de Administração Pública, v. 46, n. 5, p. 1271-1294, 2012.

REIFSCHNEIDER, Marina Becker. Considerações sobre avaliação de desempenho. Ensaio: avaliação e políticas públicas em educação, v. 16, n. 58, p. 47-58, 2008. 
SARAIVA, Luiz Alex Silva; GONÇALVES, Noeme Rodrigues. Democratização do poder local e efetividade de programas sociais: Análise de uma experiência municipal. RAC-Eletrônica, v. 2, n. 3, p. 392-409, 2008.

STRAUSS, Anselm; CORBIN, Juliet. Pesquisa qualitativa: Técnicas e procedimentos para o desenvolvimento de teoria fundamentada. Porto Alegre: Artmed, 2008.

VAN DIJK, Teun. Discurso e contexto: Uma abordagem sociocognitiva. São Paulo: Contexto. 2012.

WESTPHAL, Marcia Faria; MENDES, Rosilda. Avaliação participativa e a efetividade da promoção da saúde: desafios e oportunidades. Boletim Técnico Senac, v. 35, n. 2, p. 16-27, 2009.

Apoio:

Fundação de Amparo à Pesquisa de Minas Gerais (FAPEMIG) 